\title{
Determination of Ascorbic acid by Using a Belousov- Zhabotinsky Oscillating System Catalyzed by a Macrocylic Complex
}

\author{
Saif Ullah ${ }^{1}$, Waqar Uddin ${ }^{1}$, Gang Hu ${ }^{1 *}$, Muhammad Yasir Nawabi ${ }^{1}$, Rooh Ullah ${ }^{2}$, Saira Sardar ${ }^{3}$, \\ Muhammad Mustaqeem ${ }^{4}$, and Xiaofeng Shen ${ }^{1}$ \\ ${ }^{1}$ Department of Chemistry, Anhui University, Hefei, 230601, People's Republic of China \\ ${ }^{2}$ Department of Chemistry, University of Turbat-92600, Balochistan, Pakistan \\ ${ }^{3}$ Institute of Chemical Science, University of Peshawar, Pakistan \\ ${ }^{4}$ Department of Chemistry, University of Sargodha Sub Campus Bhakkar, Pakistan \\ *E-mail: hugang@ustc.edu
}

doi: $10.20964 / 2019.06 .07$

Received: 30 December 2018 / Accepted: 20 March 2019 / Published: 10 May 2019

\begin{abstract}
An appropriate analytical technique for determination of ascorbic acid (AA) by its perturbation effect on Belousov-Zhabotinskii (BZ) oscillating system was reported in this article. The macrocyclic copper (II) complex ( $\left.\left[\mathrm{Cul}\left(\mathrm{ClO}_{4}\right)_{2}\right]\right)$ was used as a catalyst while malic acid as substrate in $\mathrm{BZ}$ system. The ligand L in the macrocyclic-complex is 5,7,7,12,14,14-hexamethyl-1,4,8,11-tetraazacyclotetradeca-4,11-diene. Experimental outcomes shown the perturbation effect of AA could cause the change in the amplitude of oscillation $(\Delta \mathrm{A})$ and change in the period of oscillation $(\Delta \mathrm{T})$ which were directly related to its concentration $\left(3 \times 10^{-6}\right.$ to $\left.1.05 \times 10^{-4} \mathrm{M}\right)$ with correlation coefficient of 0.99 respectively. The calculated relative standard deviation (RSD) is $2.71 \%$ by eight samples $\left(1.2 \times 10^{-5} \mathrm{M}\right)$ and the observed lower limit of detection is $1.5 \times 10^{-6} \mathrm{M}$. The cyclic voltammetry $(\mathrm{CV})$ experiments were used to confirm the redox reaction between ascorbic acid and sodium bromate. Furthermore, the reaction perturbation mechanism, was derived from the well-known FKN (Field-Koros-Noyes) oscillation mechanism.
\end{abstract}

Keywords: Antioxidant; Belousov-Zhabotinskii; Chemical Oscillator; Ascorbic acid; Oscillation Amplitude

\section{FULL TEXT}

(C) 2019 The Authors. Published by ESG (www.electrochemsci.org). This article is an open access article distributed under the terms and conditions of the Creative Commons Attribution license (http://creativecommons.org/licenses/by/4.0/). 